\title{
TITLE:
}

\section{Letter : The Chimpanzees of the Chimfushi Wildlife Orphanage}

$\operatorname{AUTHOR}(\mathrm{S})$ :

\section{CITATION:}

Letter: The Chimpanzees of the Chimfushi Wildlife Orphanage. Pan Africa News 1995, 2(1): 9-11

ISSUE DATE:

1995-06

URL:

http://hdl.handle.net/2433/143312

\section{RIGHT:}

Copyright (C) Pan Africa News. 


\section{Letter}

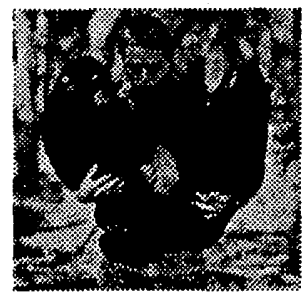

\section{The Chimpanzees of the Chimfushi Wildlife Orphanage}

In the northern part of Zambia, near the border with Zaire, lies a unique sanctuary. The Chimfushi Wildlife Orphanage for Chimpanzees. The CWO is owned and run by a remarkable couple, Dave and Sheila Siddles. Since 1983 they have dedicated their lives to the welfare of orphaned chimpanzees.

Most of the chimps brought to the CWO were confiscated from poachers and smugglers that tried to smuggle them into Zambia for the local pet trade. Others are snapped up by dealers who smuggle them out of Africa to feed the worldwide demand for pets, zoo exhibits and laboratories. Trade in chimpanzees is banned in most countries, but there is a thriving black market. The mother and any other protective relative have to be killed in order to take the offspring for sale, a pattern of waste occurring throughout Africa and resulting in five or more deaths for every chimp that reaches a local buyer. This appalling slaughter has put the chimpanzee on the road to extinction. As chimpanzees are one of the endangered species, and since poaching and destruction of their natural habitat continues to occur at an alarming rate, the work being done at places like Chimfushi is vital to their long term survival.

\section{Arrival:}

When the mostly immature chimps arrive they often have severe health problems such as malnutrition, dehydration and bodily wounds. Because they are captured in a

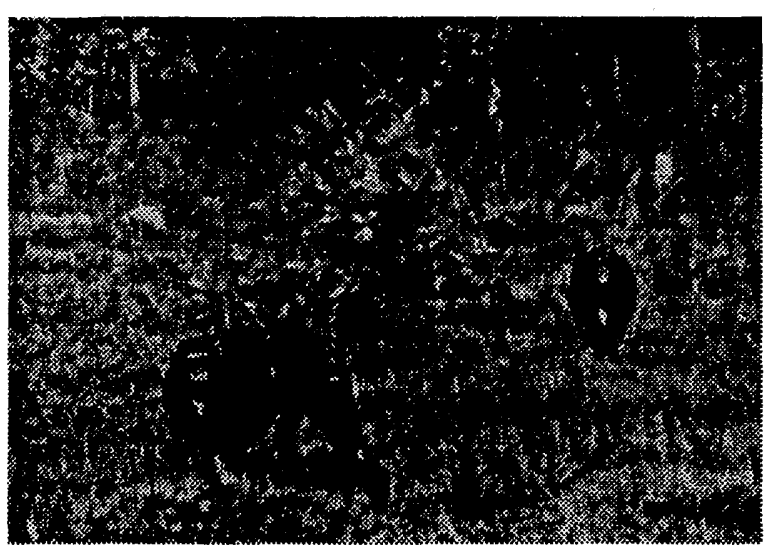

destructive manner they are also severely traumatized and suffer from various symptoms of mental social stress. Most need constant care for weeks, and sometimes months after their arrival, as well as special dietry and medical treatment. All required personal care must be provided by the Siddles themselves. It is generaly accepted by the world leading authorities that the reintroduction of displaced chimps into their natural environment where groups of wild chimps exist is virtually impossible. Because there is no hope of sending them back to their countries of origin, nor can they be released into Zambia's national parks, the Siddles had to create their own final release site. The CWO is situated on a 10,000 acre cattle ranch, bordering the Kafue and the Muchila Rivers in northern Zambia. On the farm a lot of food needed for both human and orphan wildlife consumption must be grown. The farm includes some thickly wooded areas, which because of abundance of wild fruit trees and other types of food, makes them suitable for chimps and ideal sites for the two projects that the Siddles had in mind.

\section{Project one:}

The first stage was completed in 1989. What was nick-named "the Great Wall of Zambia" took two years to build. Seven acres of prime woodland are encircled by a 


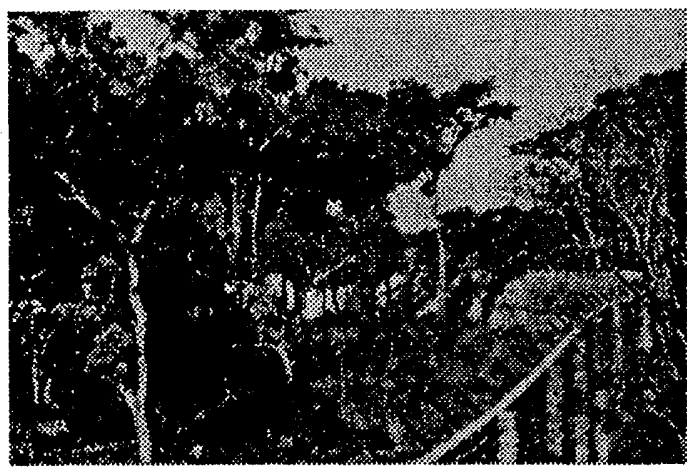

four meter high, 600 meter long wall made out of concrete blocks. The wall is sliced off at one end by the Kafue River which forms a natural barrier preventing the chimps from escaping. On top of the wall they put electric wire to prevent the chimps from climbing over. They were soon to find out though that nothing can prevent a chimp from escaping if he or she is determined to do so.

There have been built four large cages tacked on the side for feeding, isolation during sickness and protection for those chimps who would get involved in serious group conflicts. It also can be used for introducing newly arrived chimps. On top of these cages the Siddles built an observation platform so that you can look down on the chimps in the enclosure. When the enclosure was finally completed 20 chimps were released into it. Because the CWO was developing a reputation which led to international requests to accept other orphans, they soon had to anticipate for this growth. In 1991 the second enclosure was established near the first one. It contains 14 acres of bushland surrounded by an electric fence. Here also, 20 chimps were released.

\section{Daily work:}

The daily work starts at 6:30 a.m. when the chimps awake. They get their breakfast which contains cooked maize and meal balls mixed with garlic and salt. The meals are provided in the building cages. At 10:00 a.m. the latest arrivals, 6 young chimps, are taken out by their caretaker for their daily walk in the forest. The Siddles had to employ another man to look after these newcomers before they could be integrated with the other youngsters. During these walks the chimps feed on local vegetation and this provides an opportunity to learn appropriate foraging behaviour. It also serves to familiarize the chimps with local conditions in anticipation of their coming release.

When the youngsters return in the afternoon the main meal is served consisting of fresh foods such as oranges, papayas, sugarcane, cabbage, bananas, avocadoes, guava, peanuts, tomatoes, lettuce, as well as wild fruits; of which the availability varies with seasonality. At five $o^{\prime}$ clock in the afternoon all the chimps get 3 gallons of milk. After that they all make their nests for the night and soon fall asleep.

\section{Integration:}

Integration into social groups is a long and slow process. Sheila Siddle has learned from experience that the process cannot be rushed. The chimps have to learn to get together, to trust each other and to form friendships and alliances to support each other in times of trouble and conflict: Even when apparent success has been achieved, rivalries among the chimps (male or female) trying to establish their dominance in the group can cause problems. Being confined to a relatively small area, chimps can develop severe personality conflicts and may have to be removed from the group. Part of the integration process includes moving the chimps to different cages to co-habit with different partners. After some months living in the same complex, adjacent cages they can be released in the enclosure.

Since 1991 four baby chimps have been born at the sanctuary. Before the first birth took place the Siddles were a little bit worried about whether the mothers would know how to handle their babies, considering that they were very small when they were taken away from their mothers. In that case the Siddles would have to interfere. But the Siddles were soon to find out that there was no reason to be worried. All the females proved to be excellent mothers and performed the appropriate maternal duties and are raising their newborns as thriving members of the group.

\section{Meeting old friends:}

During earlier visits to the CWO I had developed a special relationship with one of the young males, Sandy. Then in 1988 he was just a naughty little boy but when I saw him again he had grown into an impressive giant. Because of repeated attempts at trying to escape from the 14 acres enclosure, he was temporarily locked up and separated from the other chimps.

Being out in the bush surrounded by a group of chimps is a lifetime experience. With one chimp in my arms and one clinging onto my back I walked into the forest. After we had walked a few hundred meters we stopped at a large termite hill. Soon they were chasing each other in and around the trees. They play with each other as they do most of the time, but on many occasions they were trying to get me involved. They used my head and back as a trampoline. They are just like children with the only difference being that they are much stronger and infatigable. Once in a while they came to sit or lie on my lap, not because they were tired but just to get some affection. They all have different personalities. In spite of 
their traumatic past, these chimps are highly intelligent and display the full range of human emotions which make them so fascinating to watch.

At this moment, 50 chimps live in these semi-wild enclosures. The final stage is to release all chimps onto 2000 acres of prime woodland near their farm. It took more than six years of negotiation and frustration before they finally were able to buy the land. An ecological study showed that compared with natural chimpanzee habitats this release site seems to be surprisingly suitable. It is wild bushland with a river running around it in the shape of a horseshoe that acts as a moat. They now need to enclose the rest probably also with an electric fence but as you can imagine this will cost a lot of money and manpower to realize. The Siddles have already invested enormous amounts of money, effort and time in this project. Despite the fact that the CWO is recognized by people like Jane Goodall and organisations like IPPL and WWF for their remarkable success in the rehabilitation of orphaned and unwanted chimpanzees into viable social family groups, it does not receive any governmental or international funding. The reason for this is that chimpanzees are not indigenous to Zambia and the work being done at CWO is considered to be humanitarian rather than conservational. Providing for 50 chimps strains the Siddles' resources and this investment cannot be maintained without some outside assistance.
Supporting groups have been founded in Sweden, England, South Africa, Germany, the Netherlands, and the USA. This year the Siddles received the Jane Goodall Award for lifetime dedication to the welfare of chimpanzees. The prize was presented to them by Jane Goodall herself during her visit to the CWO in February this year.

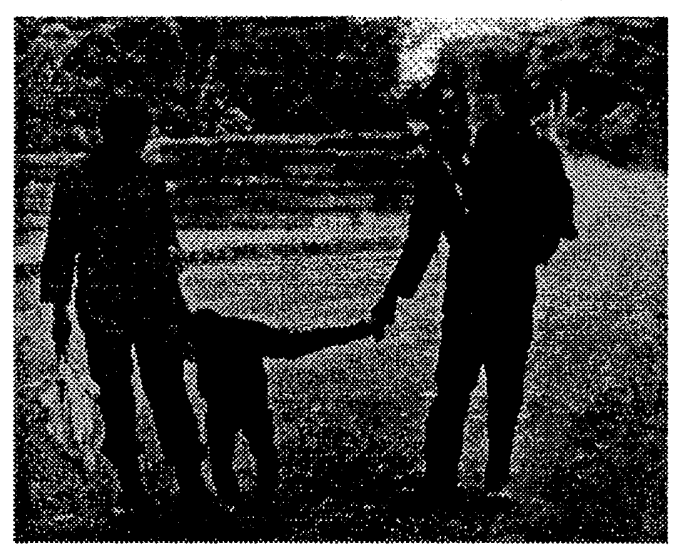

